\title{
A Cruel Homicide via Blades of a Young Boy under Custody in a Juvenile Correctional Unit
}

\author{
Murilo Sérgio Valente-Aguiar $1,2, * \mathbb{E}$, Ana Cecília Falcão ${ }^{3}$, Teresa Magalhães ${ }^{1,4}$ and \\ Ricardo Jorge Dinis-Oliveira $1,4,5, * \mathbb{D}$ \\ 1 Department of Public Health and Forensic Sciences, and Medical Education, Faculty of Medicine, \\ University of Porto, 4200-319 Porto, Portugal; tmaga@med.up.pt \\ 2 Legal Medical Institute of Porto Velho, 76803-592 Rondônia, Brazil \\ 3 Integrated Faculties of Aparício de Carvalho, 76811-678 Porto Velho, Brazil; anafalc@yahoo.com.br \\ 4 IINFACTS - Institute of Research and Advanced Training in Health Sciences and Technologies, \\ Department of Sciences, University Institute of Health Sciences (IUCS), CESPU, CRL, \\ 4585-116 Gandra, Portugal \\ 5 UCIBIO, REQUIMTE, Laboratory of Toxicology, Department of Biological Sciences, Faculty of Pharmacy, \\ University of Porto, 4050-313 Porto, Portugal \\ * $\quad$ Correspondence: up201707626@med.up.pt (M.S.V.-A.); ricardinis@med.up.pt (R.J.D.-O.)
}

Received: 27 December 2020; Accepted: 19 January 2021; Published: 4 March 2021

check for updates

\begin{abstract}
Cut-throat wounds are traumatic injuries to the anterior or lateral part of the neck, between the larynx and the hyoid bone, or over the larynx (but rarely above or below these limits), produced by a sharp and heavy instrument with a cutting edge. The depths of such wounds are variable. They can reach the spine and can be singular or multiple. The medico-legal etiology of such wounds is commonly homicide, whereas suicides are infrequent, and accidental cases are rare. In this work, we report the homicide of a 16-year-old boy in a juvenile correctional unit, whose throat was cut with cruelty using two blades. The body was then partially charred. A careful examination of the injuries along with the death scene evidence was performed to clarify the cause, circumstances, and mechanism of death.
\end{abstract}

Keywords: homicide; cut-throat wound; asphyxiation; custody; forensic autopsy

\section{Introduction}

Cut-throat wounds are a well-recognized method of homicide. These wounds are less commonly found in suicides and are rarely accidental [1-5]. Characteristic signs that help to perform differential diagnosis between homicide and suicide are the presence or absence of multiple preliminary trial cuts (i.e., hesitation incisions) by the perpetrator while gaining the courage to make a final decisive cut, the depth and orientation of the wound, signs of a fight, and the findings at the death scene investigation, but exceptions to this general pattern have also been reported [6]. Accidental cut-throat wounds occur when the victim impacts through a sheet of glass or is struck in the neck by a sharp-edged missile or flying piece of glass; they can also occur while operating a cutting machine [1,7]. In this paper, we report an unusual and cruel cut-throat homicide case of an adolescent under custody; following the cut-throat homicide, the victim was set on fire.

\section{Case Report}

A 16-year-old boy was found dead in a juvenile correctional unit in the city of Porto Velho, capital of the State of Rondônia, Brazil, where he was institutionalized several times before escaping. At least 21 records of police incidents involving his name were reported, including the theft of motorcycles, 
the receipt of stolen goods, the possession of firearms, and the possession and traffic of narcotics. Upon his last admission, the victim was housed in a room with three other males aged 16, 17, and 18. Forty-five minutes after admission, the staff of the juvenile correctional facility smelled a smokey odor. When the staff arrived, they found the victim wrapped in a burning sheet. The victim's younger 16-year-old colleague was bloody and assumed full responsibility for the murder.

The death scene investigation found, alongside the body, the cutting tools used to cause the injuries: two blades (most probably razor blades), each measuring $4 \times 0.7 \mathrm{~cm}$ at their larger axes (Figure 1).

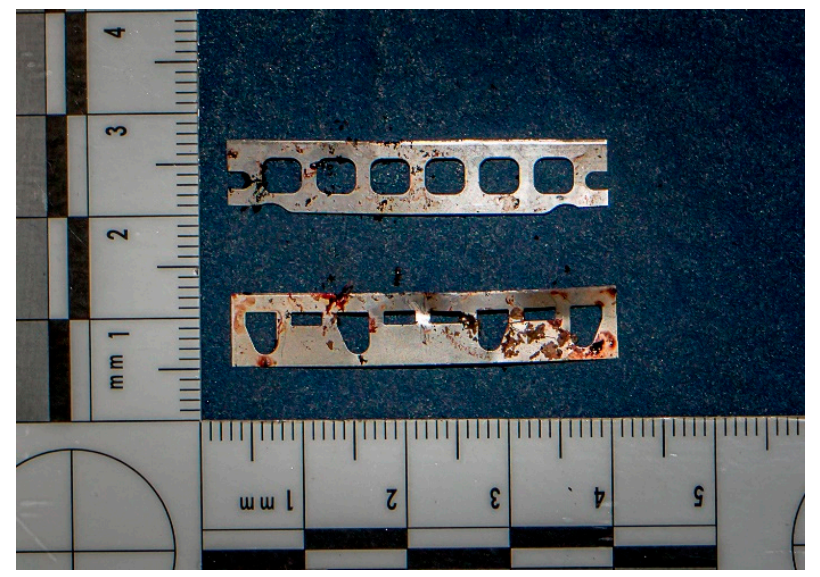

Figure 1. Two blades found at the death scene.

The autopsy was performed $15 \mathrm{~h}$ after the victim's death. The body was partially charred and presented a pugilistic stance. Signs of ligatures for body contention or defensive injuries in the hands were not evident, although they could not be excluded due to carbonization. A cut-throat wound was observed, extending from the right supraclavicular region to the left one, measuring $17 \mathrm{~cm}$ at its largest axis. The borders of the cuts were regular with a zigzag-like profile, without contusion or tissue edges, and partially charred, suggesting the action of a sharp-edged instrument. The blood infiltration of the borders and the behavior of the neck skin elastic fibers, which largely contributed to the widening of the border's thermal injuries, suggest vitality. The different orientations of some incision points were indicative of multiple cuts. A large foamy substance mixed with blood covered the internal neck structures. After cleaning the lesion, the complete sections of the carotids, jugulars, trachea, and esophagus were observed, reaching the cervical spine. The internal habit revealed blood throughout the tracheobronchial tree without the presence of soot from the fire or subpleural and subepicardial petechial hemorrhages. Toxicological analysis revealed carboxyhemoglobin of $0.97 \%$. Additional toxicological analyses were not performed.

\section{Discussion}

The occurrence of death while a person is under custody always requires a careful forensic investigation. In this study, we reported an unusual case of an adolescent homicide under custody carried out through various cuts to the neck with a hypothetical attempt to hide the evidence by charring the corpse. The blades used would not have allowed only one deep throat cut to the neck. Therefore, several cuts were likely required. Moreover, the victim was possibly held by the offenders, a finding compatible with the absence of defense injuries or ligature marks (despite carbonization).

The characteristics of cut-throat injuries can differ according to the position of the aggressor in front of or behind the victim, and forensic pathologists should be aware of the general aspects of such injuries. Cutting the neck while the offender is located behind the victim is the most common method, and the resulting lesions are similar to suicidal cut-throat wounds [3]. With the aggressor behind the victim, the victim's head is pulled back, and the throat is cut from left to right, by a right-handed 
aggressor, and from right to left, by a left-handed aggressor, with generally longer cuts. Usually, the incision starts below the ear. First, the incision runs diagonally downwards and then runs horizontally through the midline of the neck until it terminates on the opposite side of the neck. The incision ends below the point where the incision started. The lesion is deep at first, but becomes shallower on the opposite side of the neck, where one can find the wound excoriation tail [3]. In contrast, the lesions in the cut-throat that are produced when the aggressor is positioned in front of a victim tend to be short and angled. Moreover, instead of the neck being cut with a long and continuous movement, these wounds are inflicted by several cuts [3], as in the case presented.

Cut-throat injuries can lead to death, depending on the nature and extent of local damage to the neck. Severe hemorrhages from the jugular veins or, less often, the carotid arteries may cause: (i) death due to hemorrhagic shock; (ii) asphyxia due to laryngeal or tracheal aspiration/occlusion with blood, as evidenced by the large foam mushroom in our case; and, more rarely, due to (iii) gas embolism, where air enters the bloodstream through the section of the jugular veins, while the body is standing or sitting, with the neck at a higher level than the thorax [1-4,8]. Carbon monoxide intoxication was excluded in our case, suggesting that the victim was already dead when his body was partially charred, likely in an attempt to hide the injuries [9]. Indeed, carboxyhemoglobin percentages around $40 \%$ to $50 \%$ are typically considered lethal, and other findings might raise the suspicion of carbon monoxide poisoning $[9,10]$.

In Brazil, crimes in correctional facilities are increasingly committed by adolescent offenders, and most of them result in homicide [11]. Indeed, within organized crime, it is common for criminal groups to use adolescents to commit crimes since, accordingly to the Brazilian law, youths between the ages of 16 and 18 are considered to be non-imputable and not criminally responsible for murder, theft, possession of drugs, etc. [12]. In these age ranges, an educational tutelary measurement is practiced, which involves participating in socio-educational programs. Although the younger cellmate assumed full responsibility for the murder, the contribution of other members is highly plausible, at least to restrain the victim while the cuts were being performed. Moreover, since two blades with blood were recovered, there is the possibility that the cuts were performed by at least two individuals.

\section{Conclusions}

We conclude that the death was caused by the cut-throat injuries, while carbon monoxide poisoning is excluded. This case also highlights the dramatic consequences of having access to certain tools (e.g., blades and fire) within correctional units. The good quality of the forensic medical photographs provided may be useful to pathology residents or young forensic pathologists.

\section{Impact statement}

Although some publications exist regarding deaths under custody and about the medico-legal etiology of the wounds, fully characterized cases regarding the autoptic findings are rarely reported in forensic publications. This case also highlights a rare case of an homicide of a 16-year-old boy in a juvenile correctional unit, whose throat was cut with cruelty using two blades and wounds compared and discussed for homicides, suicides and accidents cases.

Author Contributions: Conceptualization, M.S.V.-A. and R.J.D.-O.; methodology related to autopsy, M.S.V.-A. and A.C.F.; validation, M.S.V.-A., T.M. and R.J.D.-O.; formal analysis, M.S.V.-A., T.M. and R.J.D.-O.; investigation, M.S.V.-A., A.C.F., T.M. and R.J.D.-O.; writing-original draft preparation, M.S.V.-A., T.M. and R.J.D.-O.; writing-review and editing, M.S.V.-A., A.C.F., T.M. and R.J.D.-O. All authors have read and agreed to the published version of the manuscript.

Funding: The authors have no relevant affiliations or financial involvement with any organization or entity with a financial interest in or financial conflict with the subject matter or materials discussed in the manuscript. The potential conflicts include employment, consultancies, honoraria, stock ownership or options, expert testimony, grants or patents received or pending, and royalties. 
Institutional Review Board Statement: All procedures were performed according to the ethical and legal standards of the institution (Legal Medical Institute of Porto Velho; protocol code 003/2020, 19th of February 2020) and the principles of the Declaration of Helsinki.

Informed Consent Statement: Typically, this type of forensic study does not require informed written or oral consent from the victims' families for scientific research conducted during routine forensic procedures. Moreover, victim identification was completely avoided and victim's mother provided a informed consent to scientific publication.

Data Availability Statement: Data in the article are in accordance with consent statement.

Conflicts of Interest: The authors have no conflict of interest to declare. No writing assistance was obtained in the production of this manuscript.

\section{References}

1. Demirci, S.; Dogan, K.H.; Gunaydin, G. Throat-Cutting of Accidental Origin. J. Forensic Sci. 2008, 53, 965-967. [CrossRef] [PubMed]

2. Ozdemir, B.; Çelbiş, O.; Kaya, A. Cut throat injuries and honor killings: Review of 15 cases in eastern Turkey. J. Forensic Leg. Med. 2013, 20, 198-203. [CrossRef]

3. Vidanapathirana, M.; Samaraweera, J.C. Homicidal Cut Throat: The Forensic Perspective. J. Clin. Diagn. Res. 2016, 10, GD01-GD02. [CrossRef]

4. Yadav, A.; Raheel, S.; Kumar, R.L.; Sharma, S.K.; Kanwar, H. Cut-throat wounds: Suicidal and homicidal-Two case reports and review of literature. Med. Sci. Law 2015, 56, 53-57. [CrossRef]

5. Ilic, I.S.G.; Milic, M.; Antovic, A.; Todorovic, S.; Jovanović, I. Unusual suicide with a chainsaw. Forensic Sci. Int. 2013, 228, e58-e61. [CrossRef]

6. Kumar, S.A.; Ms Kumar, V.; Babu, Y.R.; Prasad, M. A case of "atypical homicidal” cut-throat injury. Med. Leg. J. 2016, 84, 156-158. [CrossRef]

7. Swain, R.; Dhaka, S.; Sharma, M.; Bakshi, M.S.; Murty, O.; Sikary, A.K. Accidental cut-throat injuries from the broken windshield of an auto rickshaw: Two unusual cases. Med. Sci. Law 2018, 58, 183-185. [CrossRef]

8. Valente-Aguiar, M.S.; Dinis-Oliveira, R.J. Massive gas embolism in a child. Forensic Sci. Med. Pathol. 2019, 15, 498-501. [CrossRef]

9. Dinis-Oliveira, R.J.; Carvalho, F.; Magalhães, T.; Santos, A. Postmortem changes in carbon monoxide poisoning. Clin. Toxicol. 2010, 48, 762-763. [CrossRef] [PubMed]

10. Valente-Aguiar, M.S.; Magalhães, T.; Dinis-Oliveira, R.J. Suicide by Inhalation of Carbon Monoxide of Car Exhausts Fumes. Curr. Drug Res. Rev. 2019, 11, 145-147. [CrossRef]

11. Schorr, M.T.; Reichelt, R.R.; Alves, L.P.D.C.; Telles, B.D.B.; Strapazzon, L.; Telles, L.E.D.B. Youth homicide: A study of homicide predictor factors in adolescent offenders in custody in the south of Brazil. Trends Psychiatry Psychother. 2019, 41, 292-296. [CrossRef] [PubMed]

12. Adorno, S.; Salla, F. Criminalidade organizada nas prisões e os ataques do PCC. Estud. Avançados 2007, 21, 7-29. [CrossRef]

Publisher's Note: MDPI stays neutral with regard to jurisdictional claims in published maps and institutional affiliations.

(C) 2021 by the authors. Licensee MDPI, Basel, Switzerland. This article is an open access article distributed under the terms and conditions of the Creative Commons Attribution (CC BY) license (http://creativecommons.org/licenses/by/4.0/). 